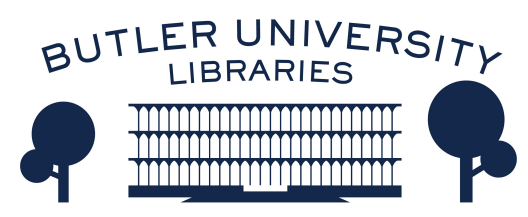

Volume 21
Journal of Hindu-Christian Studies

Article 11

January 2008

\title{
Methodological Approaches to Hindu-Christian Studies: Some Thoughts
}

\author{
T.S. Rukmani
}

Follow this and additional works at: https://digitalcommons.butler.edu/jhcs

Part of the Religion Commons

\section{Recommended Citation}

Rukmani, T.S. (2008) "Methodological Approaches to Hindu-Christian Studies: Some Thoughts," Journal of Hindu-Christian Studies: Vol. 21, Article 11.

Available at: https://doi.org/10.7825/2164-6279.1410

The Journal of Hindu-Christian Studies is a publication of the Society for Hindu-Christian Studies. The digital version is made available by Digital Commons @ Butler University. For questions about the Journal or the Society, please contact cbauman@butler.edu. For more information about Digital Commons @ Butler University, please contact digitalscholarship@butler.edu. 


\title{
Methodological Approaches to Hindu-Christian Studies: Some Thoughts
}

\author{
T. S. Rukmani \\ Concordia University
}

I was surprised that any one would want me to be a respondent for a panel which was primarily concerned with methodological approaches to Hindu-Christian Studies, my interest being mainly philosophical Sanskrit texts. However as a Hindu and having lived in India for most of my adult life I was interested to learn more about the way academics deal with this issue, which really is one fraught with many complications. Harold Coward, who gave a retrospect of the Society at the beginning of the session, did indeed give me a glimpse of the topics and methodology followed in this discipline. Harold's contribution over so many years in the area of Hindu-Christian (H-C) studies needs to be acknowledged and, in a certain sense, as I said at the meeting itself, Harold can be compared to the grandfather figure of Bhisma (Bhisma-pitamaha) in the Mahabharata (MBH). As the organizer of the first $\mathrm{H}-\mathrm{C}$ conference in 1987 at the U.of Calgary and as the first editor of the $\mathrm{H}$-C Bulletin (now called the Journal) from 1988-2002 Harold was in large measure responsible for laying down the guidelines of the journal itself, which is a bringing together of theory and lived world experience. This format has helped us understand some Hindu-Christian issues played out in India and elsewhere in their proper perspectives without being swayed one way or the other. A balanced way of presenting highly emotional and volatile issues like changing demographics and its significance for the future of India, or the attack on the BORI linked with the question of censorship, helped readers to comprehend the many-sidedness of some of these complicated themes in their proper perspective. One could assert that it is the launching of the Journal (Bulletin) in 1988, as Harold states, which assured prestige and credibility for this discipline in the academy. Harold's retrospect thus prepared me for the presentations of the other panelists.

Academic work is, by its very nature, insulated from real life situations, but when an area like Hindu-Christian Studies is concerned with topics which have implications at the ground level, I did expect a modicum of reality instilled into the presentations as well. I was, therefore, hoping that members of the panel would also address some current topics while dealing with their own methodological issues. On the other hand, Gerald Larson's comment at the end of the session that he found this $\mathrm{H}-\mathrm{C}$ Studies session no different from all the other groups like the RISA at AAR, which also deal with religious topics in a similar manner, only highlights the different perceptions that such a discipline raises in the minds of scholars. While Larson might have a point there I, on my part, was convinced that there is place in the academy for $\mathrm{H}$-C studies, as it created space for an in depth exploration of both Hinduism and Christianity in a comparative or exclusive manner.

Coming now to the presentations themselves, I did learn a lot about the different methodological approaches to Hindu Christian

Currently Professor and Chair in Hindu Studies at Concordia University, Montreal, T. S. Rukmani was earlier the first Chair of Hindu Studies and Indian Philosophy at Durban-Westville University S. Africa. She had a distinguished academic career at the University of Delhi, where her last assignment was Principal, Miranda House. Her research areas are Advaita Vedanta, Samkhya and Yoga, and topics. in Hinduism. She has a number of research papers in academic journals in both India and abroad to her credit. Her more recent book publications include The Mahabharata (2005), Yogasutrabhasyavivarana of Sankara (2 vols., 2001), and Hindu Diaspora: Global Perspectives (2001). 
Studies but was disappointed that they did not go much beyond theoretical considerations and they concentrated mainly on the past. Almost all the panelists were concerned with archival material very often from the past and when doing field work or anthropological studies relied heavily on small samples, as it is impossible by the very nature of things to have a global vision of all instances. At the same time each of the presenters was genuinely concerned with the limitations of his/her approach that manifested as a refrain in almost all the presentations especially of the younger group of the panelists (Brian, Kristin, Susan). Thus Brian advocated using other tools like "oral history", while Kristin opted for "ethnography" and Susan made an appeal for "intellectual spirituality" for doing justice to both the Hindu and Christian religious traditions.

Instead of looking only at the past, the panelists could have also looked at some of the contemporary historical issues as well within their own research methodologies. Thus they could have addressed the debate going on for quite some time now, regarding the demand of Christian converts from Hindu lower castes to be given the same kind of treatment vis-à-vis reservation of jobs etc., based on their continued impoverished status. Even leaders of the Christian churches have joined their voices to this demand without seeing the contradiction that it poses. Whatever the reasons for the continued low status of these people maybe, one needs to at least honestly answer the question why, in spite of the promises of equality in the presence of God in the Christian religion, and which might have been one of the reasons for the conversion of these people to Christianity in the first instance, the plight of these converts had not changed over centuries. Moreover, why is it that, instead of addressing that question in the context of their Christian status itself, a solution which has been evolved for underprivileged Hindus is being advocated to remedy the situation. So what did the convert to Christianity who probably came into the fold believing he/she would improve his/her social and economic status by conversion gain in the process? Do we as scholars of Hindu-Christian Studies only look at the issues that have already happened and then apply our methodologies to critically evaluate them or do we also have a role to contribute to current issues as well? There was also no coming to grips with the Pentecostal Christian movement aggressively pursuing the path of conversion in Modern India in these presentations. This also made me reflect on the way Inter-faith conversations take place nowadays. In all such meetings that I have attended, every faith practitioner invariably points out the positive sides of his/her faith and is reluctant to mention the deficiencies of their respective faiths. When I suggested at one such meeting that we should have the courage to criticize our tradition as well, it was met with some silence and much disapprobation. One person even went to the extent of saying that after all he is first and foremost a theologian and cannot change the way he looks at his own religion even though there may be defects in it.

Of course we could, on the other hand, take credit for what we all do which perhaps is creating a climate for greater acceptance of different religious approaches. We, as scholars, could even claim credit for eventually making it socially acceptable to have a Hindu prayer performed in the US Senate in recent times, in spite of the protest over it in the Senate itself from some Christian orthodox groups.

As if to remind me that things have not changed much in the world today, came the recent announcement of Pope Benedict which the $\mathrm{BBC}$ mentioned in its news broadcast on the PBS on the $6^{\text {th }}$ Dec. that all those visiting the Lourdes shrine will be automatically pardoned of all their sins. So are we back to the Middle Ages where one could buy indulgences and be assured of pardon for sins committed. Or again when the Pope mentioned that the third millennium is the time to go out and increase the fold in Asia we suddenly are faced with the brutal fact that things have not really changed that much and that we, as scholars studying Hindu Christian relations, have still to deal with the same old questions which most of us thought are no more relevant. We again might want to brush these away as not so important in absolute terms, but it is the power wielded by spiritual leaders like the Pope that carry weight amongst large numbers of people than what scholars like us do to study events after they have already occurred. 
Following Arthur Schopenhauer who once said that one's own limited vision limits one's own vision of the world, I acknowledge that I am not able to do full justice to the excellent presentations of these scholars, many of them young with bright ideas. I confess that my own vision as a philosophical Hindu limits my assessment of these very stimulating presentations concerning Hindu-Christian Studies. I will therefore comment on some of the papers again keeping in mind that religion cannot avoid the way it translates into real life situations.

When Arvind Sharma stays within textual boundaries and finds fault with those who misinterpret the New Testament textual references regarding proselytization or the superficial understanding of Christians regarding the caste duties of a Hindu, there is a complete disregard of the fact that "Religion is what religion does". If religious practices on the ground do not support the correct textual understanding of sacred texts it will not change the perceptions on both sides. As scholars we are all aware how texts can be manipulated to serve one's immediate ends, which is evident even today in religious circles. Arvind is concerned with the "ethics" of this behavior but we need to remind ourselves that when mixed with politics and issues of power, ethics can also be interpreted contextually to serve specific purposes.

There is a genuine dissatisfaction with purely theoretical approaches to $\mathrm{H}-\mathrm{C}$ studies in the academia, as almost all these scholars have come to realize and also gave expression to at the meeting. Kristin Bloomer examined in great detail the various methodologies scholars canvas for doing Hindu-Christian Studies, and her paper, originally fifty pages long, expressed genuine dissatisfaction with almost all of the methodologies by pointing out what she considers to be their shortcomings. She eventually comes to the conclusion that it is important to work with the people, which she terms is a bottom-up approach also called "theologies of the people". It appears to me that a purely theoretical approach will never yield a complete picture, as one is dealing with humans and not commodities that can be studied as the 'other'. It is this realization that makes her address, albeit marginally, the ground reality in such studies to which I allude at the beginning. Many studies these days concentrate on female divinities, and Kristin's study can be understood within the same genre even though it concentrates on Marian devotional practices of South India. What is striking in her analysis is that these women find ways of expressing their interaction with "gods, goddesses, spirits and the interaction between this spirit world and that of human persons" not in the religion of Roman Catholicism with which these women identify themselves but in their Hindu/indigenous discourses. It also brings into focus how a tradition internalizes within its own cultural understanding what is obtained from an external culture even after conversion to a new faith. Enculturated for generations within a Hindu milieu and culture it is too much to demand these converts to give up totally their earlier moorings especially when the new religion of the converts does not provide for their specific predicament, as happens in this case. This is especially relevant to the Hindu outlook which treats religion more in the realm of dharma (the way one conducts oneself) than as a religious construct, as understood in the western idiom. Even though the Hindu convert is prohibited from visiting the Hindu temple where such discourses and methods for removing them are available, they circumvent that by making use of the language in which these are conducted and seek a kind of substitute remedy for their condition. It is the same phenomenon of inclusivism that allows Hindus to visit churches as the Vellankani church in South India, the Infant Jesus shrine in Bangalore or Muslim darghas. This contrasts with the behavior of converted Christians, generally, who are asked to keep away from visiting any other place of worship other than the Christian one (cf. Vasudha Narayanan in Journal of H-C Studies vol. 17: 28). Thus though these Hindu converts of Marian devotional practices do not have the luxury of visiting the Hindu temples where such discourses and methods for removing them are available, they circumvent that by making use of the language in which these are conducted and seek a kind of substitute remedy for their condition.

This reminds me of another discipline, 
"Psychiatry," where it has been recognized that mere theoretical understanding of the disorders of the mind is not sufficient to treat the patient, but theoretical understanding informed with the patient's cultural ethos will render the treatment to be more effective than one without such an understanding (personal communication with three psychiatrists). Thus, increasingly, treatment for psychiatric patients takes into consideration the ethnic and cultural background of the patient.

Brian Pennington ruminates on how to write history within a $\mathrm{H}-\mathrm{C}$ framework. He rightly wants the horizon of the scholar doing $\mathrm{H}-\mathrm{C}$ studies to expand beyond the Indian subcontinent. This, to my mind, is a timely reminder to scholars, specially because of the fact that the Hindu Diaspora is now present in more than 150 countries in the world and it continues to face the same problems in their encounter with Christian hegemony in most of these countries. My observation comes from my having lived in South Africa in the early 1990s where I have had first hand experience of this nature.

Susan Abraham's paper again deals with some of these concerns though not spelt out in so many words. She talks about how the west is not able to understand the "hybridity of identity" that Homi Bhabha talks about, because of a lack of " acceptable reasoning" for practicing "intellectual spirituality based on culture". "Intellectual Spirituality" based on culture is the key concept here, and to my mind Susan is pushing strongly for an acknowledgement of cultural underpinnings in $\mathrm{H}-\mathrm{C}$. Studies and supports what I stated earlier. She talks about a new way to study this discipline which is to enter into a dialogue "in a mode of ascesis of the ego". Is Susan referring to a kind of Hindu "samadhi," I ask myself? But in a sense she is talking about transcending the 'ego' in order to be able to appreciate another culture and extend it to understand both the religions. If I understand her correctly, Susan thus calls into question the very rationale of conversion as a radical change of identity as advocated by missionaries. However, how would Susan answer the question of a converted Hindu not being allowed to visit a Hindu temple which she used to do regularly before conversion, if she follows her method of "Intellectual Spirituality" I ask myself. The answer comes when she argues for an "inclusivist third space" that Hinduism can easily provide for Christians, which flies in the face of "the arguments of bounded identity". This accords with the view of being able to acknowledge what is good in the religions we are studying and adopting it for harmonious understanding between peoples.

In conclusion I would like to state what I have all along felt, which is that there is a heavy reliance on theoretical models for the academic study of H-C Studies which by its very nature cannot be confined to theoretical models alone. Moreover it is a truism that historiography is written from the standpoint of the author and has to that extent a subjectivity and is not entirely neutral. This, perhaps, can never be overcome as long as humans have their pet likes and preferences. But that cannot be made an excuse for not studying these phenomena, and so the effort continues. Secondly, I also feel that the theoretical frames used by scholars mainly developed in the West and tacitly accept Western cultural norms (more western scholars are engaged in religious studies than their Indian counterparts). To counteract this, it would be a good idea to look at not only Indian theologians but also at other Indian Christians who are not theologians, engaged in the study of religion as a discipline. It will also be beneficial to look at the writings of Hindu scholars who look at these questions from a different perspective altogether. Religion is too precious a commodity to be left to the study only by theologians and religious studies academics. It is something that belongs to everyone and in which all have some interest including, I would add, even the atheists, albeit marginally as a curiosity. Thus it would be a good idea for $\mathrm{H}-\mathrm{C}$ scholars to also look at some of the writings of Christians like Ashish Nandy or Hindu scholars like Arun Shourie to see how the others "see us". Theologians, whether Indian or Western, working within their own religious boundaries, may be suffering from a kind of myopia. Looking outside one's own field and trying to understand an outside perspective may help us find a different way of approaching this discipline, acknowledging at the same time that, whatever the method followed, it will always fall short of what we want, because this 
is a Human Science. But that should not prevent us from trying to approach the discipline in as many ways as possible. 